\title{
KONSERVASI TUMBUHAN OBAT KALIMANTAN TIMUR DALAM PERSPEKTIF KEHUTANAN DAN LINGKUNGAN HIDUP "PENGGALIAN, PEMANFAATAN DAN PEMANFAATAN BERKELANJUTAN"
}

\author{
Suryanto $^{1}$, Ahmad Gadang Pamungkas ${ }^{2}$, Teguh Muslim ${ }^{3}$ \\ ${ }^{1}$ Balai Penelitian Teknologi KSDA, Samboja; suryantoflitce@ gmail.com, 082157162990; \\ ${ }^{2}$ Balai Penelitian Teknologi KSDA, Samboja; gadang_p@yahoo.com, 082190019695; \\ ${ }^{3}$ Balai Penelitian Teknologi KSDA, Samboja; tm97_forester@yahoo.com, 082158583665
}

\begin{abstract}
ABSTRAK
Kesehatan, kapital, hak intelektual dan pemanfaatan tumbuhan obat yang bersumber dari hutan adalah hal menarik diulas dalam tulisan ini. Upaya penggalian, pemanfaatan dan pemanfaatan berkelanjutannya bagaimanapun berkaitan erat dengan isu-isu tentang kondisi ruang hutan yang menyempit, eksploitasi dan upaya konservasinya. Tulisan ini menyediakan konsep pikir terkait isu-isu tersebut dan tentang upaya mengelola potensipotensi tumbuhan obat di Indonesia dengan arah yang lebih baik.
\end{abstract}

Kata Kunci : Tumbuhan obat, Konservasi tumbuhan obat, Penggalian dan pemanfaatan tumbuhan obat

\section{A. PENDAhUluan}

Hutan memiliki fungsi sangat penting bagi kehidupan di bumi. Dalam hal kesehatan manusia, hutan menjadi salah satu sumber daya utama dalam penggalian materi dan pengetahuan tentang obat. Diketahui bahwa dari hasil survey 150 jenis obat beresep yang umum digunakan di Amerika Serikat, sebanyak 57\%-nya mengandung sedikitnya satu senyawa aktif yang didapat dari alam. Sebagian besar di antaranya didapat dari hutan tropis, yang diantaranya meliputi senyawa kontrasepsi, pengendur otot, senyawa anti bakteri, aprodisiak, dan obat-obatan yang digunakan untuk mengobati gagal jantung, malaria, kanker, dan penyakit lainnya (Cifor, 2007).

Terkait hutan dalam perspektif ruang, deforestasi dan degradasi hutan yang tinggi telah menyempitkan ruang hutan untuk keperluan penggalian materi tumbuhan obat. Deforestasi telah mengurangi 30\% hutan Indonesia, dari jumlah luas 162 juta ha pada tahun 1960-an menjadi 108 juta ha pada tahun 2015. Sebagian kawasan yang tersisa bahkan dalam kondisi terdegradasi. Degradasi adalah kerusakan hutan yang diakibatkan oleh aktifitas pembalakan yang tidak ramah lingkungan, perambahan dan kebakaran. Kompas (2015) menyebutkan angka kerusakan sebesar 43 juta ha, yang menurut data rilis Kementerian Lingkungan Hidup dan Kehutanan (KLHK), sejumlah 27,6 juta ha rusak berat atau dalam status tidak bertutupan hutan (KLHK, 2015).

Dalam perspektif lain, daya dukung hutan ikut melemah akibat perilaku yang eksploitatif dalam pengambilan materi tumbuhan sebagai bahan baku obat dari hutan. Perilaku ini diantaranya telah menyebabkan setengah dari 20.000 jenis tumbuhan obat yang digunakan dan berhabitat di hutan tropis terancam punah (Cifor, 2007). Selain itu, ada sejumlah besar kontroversi tentang profit sharing yang diperoleh masyarakat tradisional yang hidup di sekitar hutan. Per-kembangan pesat industri farmasi saat sekarang mengakar dari pengetahuan pengobatan tradisional dari etnis lokal (Mans, 2013 dalam Widuri, dkk. 2014), namun demikian, apresiasi terhadap sumber pengetahuan ini 
sangat kecil dan tidak memberi dampak yang signifikan untuk peningkatan kesejahteraan masyarakat.

Tulisan ini bertujuan untuk menyampaikan beberapa ulasan terkait tiga isu utama dalam uraian di atas. Ulasan ini dihasilkan melalui studi literatur dan pemahaman umum tentang aspek penting kesehatan manusia dan pelestarian sumber daya alam hutan. Di harapkan beberapa hasil yang disampaikan dapat mempengaruhi proses penyusunan strategi penggalian, pemanfaatan dan pemanfaatan berkelanjutan tumbuhan obat dalam perspektif konservasi dan pemanfaatannya yang lestari.

\section{B. HUTAN DAN FUNGSI ESENSIAL}

Hutan adalah sumberdaya alam yang didominasi pleh pepohonan sebagai struktur utama bangunan hutan. Walau didominasi, hutan tidak sekedar cerita tentang pepohonan, kayu dan pembalakan. Ada ikatan saling ketergantungan antara pohon dengan beragam sumberdaya hayati dan non hayati dalam ekosistem hutan. Ekosistem yang terbangun sangat kompleks dan memberi fungsi-fungsi yang esensial bagi manusia. Dalam hal ini, Gardner dan Engelman (1999) menjabarkannya dalam 9 fungsi esensial. Selain menyediakan sumber bahan baku kayu untuk papan, kertas (1) dan energi (2), hutan juga memberi perlindungan tata air (3), penyimpan karbon dan penyedia udara bersih (4) serta rekreasi (5) dan cadangan lahan untuk pertanian (6). Tiga fungsi esensial lainnya adalah sebagai tempat tinggal masyarakat yang hidup secara subsisten (7), penyedia hasil hutan bukan kayu untuk bahan pangan, obat-obatan, kosmetika dan lainnya (8) serta habitat dan konservasi beragam jenis tumbuhan dan hewan yang menyimpan potensi plasmanutfah yang dapat dimanfaatkan sebagai sumber makanan, obat-obatan dan berbagai keperluan pendidikan serta pengembangan ilmu dan teknologi, baik yang digunakan saat sekarang maupun untuk penggunaan generasi berikutnya (9).

Negara melalui UU no 41 tentang Kehutanan (PRI ${ }^{\mathrm{a}}$, 1999) mengamanatkan untuk mengoptimal-kan aneka fungsi hutan tersebut untuk kesejahteraan rakyat. Negara dalam hal menetapkan kelestarian dan keseimbangan sebagai asas dalam pemanfaatan hutan. Salah satu imple-mentasinya adalah dengan membagi dan mempertahankan kawasan hutan dalam 3 fungsi utama, yaitu: (1). Kawasan hutan sebagai Suaka Alam dan Pelestarian Alam (KSA_KPA), (2) Kawasan hutan sebagai Hutan Lindung (HL) dan (3) Kawasan hutan sebagai Hutan Produksi (HP). Sebagian kawasan hutan lain telah dicadangkan untuk lahan pertanian, perkebunan dan pemukiman. Kawasan yang dicadangkan ini dikategorikan sebagai Kawasan Hutan Produksi yang dapat dikonversi (HPK). Lihat Tabel 1 .

\section{RUANG HUTAN UNTUK PENGGALIAN POTENSI TUMBUHAN OBAT}

Sayangnya, sejarah kelola hutan di Indonesia dimulai dengan semangat yang eksploitatif pada dekade akhir 1960an dan mengalami puncaknya pada dekade 1970-80an. Hutan secara psikologis terlanjur dimaknai sebagai mutiara hijau dan menempatkan objek pohon sebagai hasil utama dari hutan. Pohon-pohon ditebang untuk mendapatkan Hasil Hutan Kayu (HHK). Proses destruktif ini melepaskan ikatan pohon dengan ekosistemnya. Banyak aktifitas pembalakan dilakukan secara tidak hati-hati, yang dampaknya tidak sekedar bicara tentang kehilangan pohon tapi juga tentang kerusakan hutan. Permasalah kerusakan ini masih berlanjut pada dekade sekarang. Aktifitas okupasi hutan secara legal atau illegal untuk perkebunan dan pertambangan ikut menambah masalah kehilangan hutan alam di Indonesia. Kumulasi dampak ini di antaranya telah menempatkan hutan hujan tropis Sumatera dalam daftar situs dunia yang terancam (Hadian, 2010). Bisa jadi hutan tropis di Kalimantan dan Papua akan mengalami hal yang sama. Saat sekarang, 56 juta ha 
kawasan hutan berpotensi terancam okupasi untuk pertambangan dan perkebunan (Kaltim Post, 2016).

Sebagai habitat, hutan tropis Indonesia menyimpan kekayaan jenis yang sangat tinggi. Primack et al (1998) dalam Gunawan dan Mukhlisi (2014) menempatkan Indonesia dalam urutan ketiga dari 10 negara dengan mega-biodiversitas di dunia. Sebanyak $80 \%$ kekayaan hayati tersebut berhabitat hidup di hutan. Diantaranya terdapat 39.000 kekayaan jenis tumbuhan; 9.600 jenis tumbuhan tersebut teridentifikasi sebagai tumbuhan berkhasiat obat (Kemenkes, 2013). Sejauh ini, kelola Hasil Hutan Bukan Kayu (HHBK) yang didalamnya termasuk tumbuhan obat adalah bagian minor dalam pengelolaan hutan Indonesia, yang menempatkannya sebagai sumberdaya yang terdampak dari kerusakan hutan.

Setiap orang berhak atas kesehatan dan pemerintah bertanggung jawab atas ketersediaan sumber daya di bidang kesehatan yang adil dan merata bagi seluruh masyarakat untuk memperoleh derajat kesehatan yang setinggi-tingginya. Dalam hal ini, pemerintah berkewajiban memelihara sumber sediaan farmasi yang berasal dari alam (hutan) (PRI, 2009). Tiga dari delapan komponen kegiatan dalam aspek budidaya dan konservasi sumberdaya obat tradisional (Kemenkes, 2007) diantaranya menyebutkan aspek konservasi, pemberdayaan masyarakat dan pembentukan bank plasma nutfah/sumber genetiK tumbuhan obat. Tiga komponen ini berkaitan dengan ruang, yangmana dalam kondisi negatifnya, hutan Indonesia masih menjadi referensi ruang untuk penggalian, pemanfaatan dan pemanfaatan berkelanjutan tumbuhan obat. Tabel 1 berikut menjelaskan ruang hutan tersisa yang potensial untuk aktifitas penggalian, pemanfaatan dan pemanfaatan berkelanjutan.

Tabel 1. Kondisi tutupan hutan Indonesia serta Kalimantan Timur dan Kalimantan Utara

\begin{tabular}{|c|c|c|c|c|c|c|}
\hline \multirow{2}{*}{$\begin{array}{c}\text { Klasifikasi } \\
\text { Tutupan Hutan }\end{array}$} & \multicolumn{3}{|c|}{ Kawasan Hutan (x1000 Ha) } & \multirow{2}{*}{$\begin{array}{c}\text { Jumlah } \\
\text { Kaw. } \\
\text { Hutan } \\
\text { (x1000ha) }\end{array}$} & \multirow{2}{*}{$\begin{array}{c}\text { HPK } \\
\text { (x1000ha) }\end{array}$} & \multirow{2}{*}{$\begin{array}{c}\text { Jumlah } \\
\text { Kaw.Hutan } \\
\text { dan HPK }\end{array}$} \\
\hline & $\begin{array}{l}\text { KSA- } \\
\text { KPA }\end{array}$ & HL & HP & & & \\
\hline \multicolumn{7}{|l|}{ INDONESIA } \\
\hline $\begin{array}{l}\text { Hutan Alam } \\
\text { Primer }\end{array}$ & $12.521,3$ & $14.694,1$ & $14.579,5$ & $41.794,9$ & $2.957,3$ & $44.752,2$ \\
\hline $\begin{array}{l}\text { Hutan Alam } \\
\text { Sekunder }\end{array}$ & $4.885,3$ & $9.085,8$ & $21.406,4$ & $35.377,5$ & 4473,6 & $39.851,1$ \\
\hline Hutan Tanaman & 136,6 & 311,0 & $3.193,4$ & $3.641,0$ & 79,2 & $3.720,2$ \\
\hline Tidak berhutan & $4.452,8$ & $5.826,6$ & $17.404,6$ & $27.684,0$ & $8.015,4$ & $35.699,4$ \\
\hline JUMLAH & $21.996,8$ & $29.917,6$ & 56.583 .9 & $108.497,4$ & $15.525,4$ & $124.022,8$ \\
\hline \multicolumn{7}{|c|}{ KALIMANTAN TIMUR dan UTARA } \\
\hline $\begin{array}{l}\text { Hutan Alam } \\
\text { Primer }\end{array}$ & $1.203,5$ & $2.117,1$ & $2.646,9$ & $5.967,5$ & 5,0 & $5.972,5$ \\
\hline $\begin{array}{l}\text { Hutan Alam } \\
\text { Sekunder }\end{array}$ & 237,8 & 623,7 & $4.120,5$ & $4.981,9$ & 93,1 & $5.075,1$ \\
\hline Hutan Tanaman & 0,0 & 0,4 & 310,4 & 310,8 & 1,3 & 312,1 \\
\hline Tidak berhutan & 300,1 & 125,9 & 2.080 & 2.506 .0 & 86,8 & $2.592,7$ \\
\hline JUMLAH & $1.741,4$ & $2.867,1$ & $9.157,7$ & $13.766,3$ & 186,2 & $13.952,5$ \\
\hline
\end{tabular}

Sumber : KLHK, 2015_Statistik Kementerian Lingkungan Hidup dan Kehutanan tahun 2014

Hutan primer adalah hutan dengan ekosistem yang masih perawan dan tidak terganggu. Dalam kondisi tidak terganggu, kelimpahan jenisnya lebih tinggi dibanding 
tipe tutupan hutan lainnya. Sehingga demikian, peluang ditemukannya jenis-jenis tumbuhan obat baru di hutan primer adalah lebih tinggi. Berdasarkan olahan data statistik kehutanan di atas, kesediaan kawasan hutan primer di Indonesia yang dapat menjadi destinasi untuk penggalian potensi tumbuhan obat adalah seluas 41,7 juta ha. Presentasi terbesar di kawasan konservasi (65\%); meliputi Kawasan Suaka Alam (KSA), Kawasan Pelestarian Alam (KPA) dan Hutan Lindung (HL).

Di Kalimantan Timur dan Utara jumlah luas hutan primer adalah sebesar sebesar 5,9 juta ha, 56\%-nya berada di Kawasan Konservasi. Dua Taman Nasional (TN) di Kalimantan Timur/Utara direkomendasikan menjadi destinasi untuk tujuan penggalian tumbuhan obat. Potensi terbesar adalah di TN. Kayan Mentarang yang memiliki luas 1.306.600 ha. Berbeda dengan TN Kutai, TN Kayan Mentarang tidak memiliki permasalahan tentang okupasi yang berat. Walaupun demikian, aksesibilitas TN Kutai yang lebih memadai tetap menempatkannya sebagai destinasi. TN Kutai memiliki luas 198.629 ha. Dalam skala yang lebih kecil, Kalimantan Timur juga memiliki 2 KHDTK yang prospektif untuk destinasi penggalian. Dua KHDTK tersebut adalah KHDTK Labanan dengan luas 7.900 ha yang terletak di Kabupaten Berau dan KHDTK Samboja dengan luas 3.500 ha yang terletak di Kabupaten Kutai Kertanegara.

Disamping rujukan destinasi tersebut di atas, kawasan dalam kelola hutan produksi tetap menyediakan peluang untuk penggalian, termasuk untuk upaya kelola bank plasma nutfah. BPS (2015) menyajikan data bahwa di Kalimantan Timur dan Utara terdapat 65 Ijin Usaha Pengelolaan Hasil Hutan Kayu di Hutan Alam (IUPHHK-HA) yang masih aktif dengan total luas 4,7 juta ha. Dalam hal ini, masing-masing IUPHHK diregulasikan harus menyedia Kawasan Pelestarian Plasma Nutfah (KPPN) minimal seluas 300 ha per unit IUPHHK. Dengan asumsi penetapannya mengikuti kaidah yang tepat, potensi luas yang dapat dimanfaatkan untuk pelestarian plasma nutfat tumbuhan obat di hutan produksi Kalimantan Timur dan Utara adalah sebesar 19.500 ha. Isu-isu nasional tentang ketahanan pangan serta pengembangan Forest Cluster Industri (FCI) di sektor kehutanan adalah peluang ruang untuk dilakukannya usaha budidaya tumbuhan obat di kawasan hutan produksi. Aditama, YT (2014) menyampaikan bahwa jenis Kepel (Stelechocarpus burahol Hook.F.\&Th), Secang (Caesalpinia sappan), Temulawak (Curcumaxanthorrhiza Roxb), Kunyit (Curcuma domestica) dan Kumis Kucing (Orthosiphon aristatus Thunb) telah memiliki saintifik jamu. Jenis-jenis tersebut bersama jenis lainnya yang telah dikuasai aspek budidayanya, seperti Mengkudu (Bancudus latifolia), Mimba (Azadirachta indica), pasak bumi (Eurycoma longifolia), Kemiri (Aleurites moluccana), Manggis (Garciniae mangostanae), Kemuning (Murraya exotica), Kayu putih (Melaleuca leucadendron) dan beberapa jenis lainnya berpeluang untuk dikembangkan di sebagian lahan di dalam unit IUPHHK. Peluangnya bahkan memiliki potensi untuk dikembangkan dalam mekanisme bermitra dengan masyarakat sekitar untuk meningkatkan kesejahteraannya.

\section{MINIMNYA UPAYA EKSPLORASI TANAMAN OBAT DI KAWASAN HUTAN}

Pasar herbal dunia pada tahun 2008 adalah sekitar US\$ 60 milyar. Nilai pasar tersebut akan terus meningkat dan diperkirakan mencapai US\$ 150 milyar pada tahun 2020. Dari total nilai perdagangan produk herbal yang berasal dari tumbuhan obat dunia tersebut, omzet penjualan produk herbal Indonesia baru mencapai US\$ 100 juta per tahun atau sebesar 0,22\% pangsa dunia (Aditama, 2014). Kemenkes (2007) menjabarkan bahwa sumber daya alam bahan obat dan obat tradisional merupakan aset nasional yang perlu terus digali, diteliti, dikembangkan dan dioptimalkan pemanfaatannya. Sebagai suatu negara dengan wilayah yang mempunyai tingkat keanekaragaman hayati yang tinggi, potensi sumber data tumbuhan yang ada merupakan suatu aset dengan nilai keunggulan 
komparatif dan sebagai suatu modal dasar utama dalam upaya pemanfaatan dan pengembangannya untuk menjadi komoditi yang kompetitif.

Kegiatan penelitian mendapat proporsi penting dalam strategi pengembangan tumbuhan obat dan penyediaan bahan baku obat. Kemenkes (2013) memaparkan bahwa kegiatan penelitian dan pengembangan Bahan Baku Obat Tradisional (BBOT) simplisia dan ekstrak dilakukan melalui tahapan :

1. Kegiatan seleksi, karakterisasi konservasi bibit tanaman obat

2. Budidaya tanaman obat yang memenuhi ketentuan good agricultural practice (GAP)

3. Teknologi pasca panen untuk menghasilkan simplisia terstandar, mengacu pada Materia Medika Indonesia dan Farmakope Herbal Indonesia

4. Fitokimia, untuk kebutuhan penetapan parameter spesifik simplisia dan esktrak mengacu pada Materia Medika Indonesia, Monografi Ekstrak dan Farmakope Herbal Indonesia

5. Teknologi ekstraksi untuk menghasilkan teknologi proses produksi ekstrak terstandar

6. Uji praklinik, meliputi uji in vitro dan uji in vivo, mengacu pada Buku Pedoman Uji Praklinik (diterbitkan oleh BPOM)

7. Uji klinik pada manusia mengacu pada Buku Pedoman Uji Klinik Obat Herbal (diterbitkan oleh BPOM)

Kemenkes (2013) menjelaskan permasalahan lain, yaitu industri ekstrak bahan alam (IEBA) sejauh ini masih belum ditopang dengan industri simplisia modern yang mampu menjamin ketersediaan dalam jenis, jumlah dan mutu yang diinginkan. Berkenaan dengan hal ini, aspek penting dalam menjamin ketersediaan tersebut dimulai dari aktifitas eksplorasi, baik untuk penemuan jenis baru maupun untuk mendapatkan sentra-sentra baru sumber bahan baku tumbuhan obat.

Selanjutnya, dua dari empat tujuan disusunnya kebijakan obat tradisional nasional (kontranas) dalam Kemenkes (2007) adalah mendorong pemanfaatan sumber daya alam dan ramuan tradisional secara berkelanjutan (sustainable use) dan menjamin pengelolaan potensi alam Indonesia secara lintas sektor. Sebagai pengelola sumberdaya hutan, kesiapan Kementerian Lingkungan Hidup dan Kehutanan (KLHK) tentunya diperlukan dalam mendukung kontranas ini. Permasalahan utama yang hadir adalah peran KLHK tidak teridentifikasikan dalam kontranas. Selain lembaga pendidikan tinggi, beberapa lembaga yang dirujuk perannya adalah Kementerian Pertanian, Kementerian Perindustrian, Lembaga Ilmu Pengetahuan Indonesia, BPPT, BATAN dan Kementerian Kesehatan. Kehilangan peran ini adalah kritik untuk KLHK atau Kontranas.

Terlepas dari peran yang tidak teridentifikasi, kesiapan KLHK dalam mendukung kelola tumbuhan obat adalah cukup memadai. Terutama dalam hal kesiapan kebijakan dan ketersediaan kelembagaan. Beberapa peraturan-perundangan terkait kehutanan yang menjadi landasan hukumnya adalah :

1. Undang-undang Nomor 5 tahun 1990 tentang Konservasi Sumber Daya Alam Hayati dan Ekosistemnya

2. Undang-undang Nomor 41 tahun 1999 tentang Kehutanan

3. Peraturan Pemerintah Nomor 8 Tahun 1999 Tentang Pemanfaatan Jenis Tumbuhan dan Satwa Liar

4. Peraturan Pemerintah Nomor 6 Tahun 2007 jo No. 3/2008 Tentang Tata Hutan Dan Penyusunan Rencana Pengelolaan Hutan, Pemanfaatan Hutan Dan Penggunaan Kawasan Hutan

5. Peraturan Menteri Kehutanan Nomor 35 Tahun 2007 Tentang Hasil Hutan Bukan Kayu

6. Peraturan Direktur Jenderal RLPS Nomor P.14/V-Set/2007 Tentang Pedoman Pengembangan Hasil Hutan Bukan Kayu 
Peraturan-peraturan perundangan tersebut telah mengatur penyediaan ruang untuk penggalian dan prosedur pemanfaatan sumberdaya hutan, baik dalam hal kelola kawasannya maupun pemanfaatan jenis tumbuhan, termasuk jenis yang dilindungi. Di antaranya telah disediakan Kawasan Konservasi yang meliputi Kawasan Suaka dan Pelestarian Alam (KSA-KPA), Hutan Lindung dan Hutan Produksi yang bisa dimanfaatkan.

Kawasan Suaka Alam adalah hutan yang dengan ciri khas tertentu, yang mempunyai fungsi pokok sebagai kawasan pengawetan keanekaragaman tumbuhan dan satwa serta ekosistem-nya, yang juga berfungsi sebagai wilayah penyangga kehidupan. Termasuk dalam kategori kawasan ini ialah Cagar Alam (CA) dan Suaka Margasatwa. Kedua kategori kawasan tersebut dilindungi secara ketat, sehingga tidak boleh ada sedikitpun campur tangan manusia dalam proses-proses alami yang terjadi di dalam kawasan tersebut. Kawasan ini hanya diperuntukkan bagi keperluan ilmu pengetahuan dan pendidikan. Saat ini terdapat 245 unit Cagar Alam Darat dengan total luas 3,96 juta ha. Suaka Margasatwa darat sebanyak 71 unit dengan luas 5,02 juta ha (KLHK, 2015).

Kawasan Pelestarian Alam adalah hutan dengan ciri khas tertentu yang mempunyai fungsi pokok perlindungan sistem penyangga kehidupan, pengawetan keanekaragaman jenis tumbuhan dan satwa, serta pemanfaatan secara lestari sumberdaya alam hayati dan ekosistemnya. Termasuk ke dalam kategori kawasan ini adalah Taman Nasional, Taman Wisata Alam dan Taman Hutan Raya. Taman Nasional merupakan kawasan pelestarian alam yang mempunyai ekosistem asli yang dikelola dengan sistem zonasi untuk keperluan ilmu pengetahuan, pendidikan, penunjang budidaya tumbuhan dan/atau satwa, pariwisata, dan rekreasi. Saat ini terdapat 50 unit Taman Nasional dengan jumlah luas 14,3 juta ha. Taman Wisata Alam adalah kawasan pelestarian alam dengan tujuan utama untuk dimanfaatkan bagi kepentingan pariwisata dan rekreasi alam. Saat ini terdapat 115 unit Taman Wisata Alam dengan luas 748 ribu ha. Taman Hutan Raya merupakan kawasan pelestarian alam yang ditetapkan untuk tujuan koleksi tumbuh-tumbuhan dan/atau satwa yang alami atau bukan alami, dari jenis asli atau bukan asli, yang dimanfaatkan bagi kepentingan penelitian, ilmu pengetahuan, pendidikan, penunjang budidaya tumbuhan dan/atau satwa, budaya, pariwisata, dan rekreasi. Terdapat 23 unit Taman Hutan Raya dengan luas total sekitar 352 ribu ha. Taman Buru adalah kawasan hutan yang ditetapkan sebagai tempat wisata buru, yang terdiri dari 13 unit Taman Buru dengan total luas sekitar 221 ribu ha (KHK, 2015).

Berdasarkan uraian definisi di atas, keberadaan kawasan hutan, termasuk hutan konservasi dan lindung tidak membatasi ruang gerak dalam penggalian. Konsepsi ini dilandaskan pada definisi konservasi sumber daya alam hayati itu sendiri, yang mana menurut Undang-undang No. 5 (PRI, 1990) adalah pengelolaan sumber daya alam hayati yang pemanfaatannya dilakukan secara bijaksana untuk menjamin kesinambungan persediaannya dengan tetap memelihara dan meningkatkan kualitas keanekaragaman dan nilainya. Pemanfaatan jenis tumbuhan dan satwa liar dilakukan dengan memperhatikan kelangsungan potensi, daya dukung, dan keanekaragaman jenis tumbuhan dan satwa liar. Konservasi dalam konseptualnya adalah mengatur bentuk pemanfaatan sesuai dengan status kawasan dan status jenis. Seperti yang dipaparkan dalam Peraturan Pemerintah No. 8 tahun 1999 ( $\mathrm{PRI}^{\mathrm{b}}$, 1999); pengkajian, penelitian dan pengembangan dapat dilakukan terhadap jenis tumbuhandan satwa liar yang dilindungi atau yang tidak dilindungi. Penggunaan jenis tumbuhan dan satwa liar yang dilindungi untuk kepentingan pengkajian, penelitian dan pengembangan harus dengan izin Menteri. Selain itu pengambilan tumbuhan liar dan penangkapan satwa liar dari habitat alam untuk keperluan pengkajian, penelitian dan pengembangan diatur lebih lanjut oleh Menteri. 
Kemungkinan sebagai penyebab atau sebagai akibat, fakta yang tersedia adalah kawasan hutan sejauh ini tidak menjadi destinasi yang dioptimalkan untuk penggalian, pemanfaatan dan pemanfaatan berkelanjutan tumbuhan obat. Merujuk pada data kunjungan untuk penelitian dan pengembangan di kawasan konservasi, aktifitas yang mendukung strategi dalam kontranas di kawasan hutan teridentifikasi sangat kecil. Jumlah kunjungan di 50 Taman Nasional untuk tujuan penelitian pada tahun 2014 hanya sebesar 3.975 kunjungan, dengan rata-rata 80 kunjungan. Sebanyak 1.113 kunjungan terjadi di Taman Nasional Gede Pangrano. Untuk dua Taman Nasional di Kalimantan Timur dan Utara, jumlah kunjungan hanya sebanyak 37 aktifitas untuk TN Kutai dan 4 aktifitas untuk Kayan Mentarang. Cagar Alam bahkan tidak menjadi destinasi yang signifikan. Hanya 36 dari 245 Cagar Alam di Indonesia yang mendapat kunjungan untuk tujuan penelitian pada tahun 2014 dengan jumlah aktifitas sebanyak 508. Sebanyak 50\% terkonsentrasi ke CA Pulau Anak Krakatau (217) dan CA Kawah Kamojang (40). Sebanyak 209 Cagar Alam, termasuk 4 yang ada di Kalimantan Timur/Utara tidak tercatat mendapat kunjungan untuk penelitian. Empat CA di Kalimantan Timur/Utara tersebut adalah Muara Kaman Sedulang (62.500 ha), Padang Luway (4.896 ha) dan Teluk Apar (46.900 ha). Teluk Adang (62.402 ha). Demikian juga untuk Kawasan Konservasi lainnya; dari 75 Suaka margasatwa yang ada, hanya 11 yang mendapat kunjungan penelitian dengan jumlah 39 kunjungan. Suaka Margasatwa Pulau Semama (220 ha) di Kalimantan Timur tidak mendapat kunjungan penelitian.

\section{E. DISKUSI}

Diskusi ini dimulai dengan argumentasi bahwa keinginan setiap manusia untuk sehat melahirkan sebuah adagium "sehat itu mahal". Adagium ini menyampaikan fakta bahwa industri obat-obatan dan farmasi, termasuk didalamnya kosmetika adalah sebuah industri dengan perputaran uang yang sangat-sangat besar. Dalam perspektif berbeda, kapital mempengaruhi sikap koorporasi atau perseorangan dalam penemuan bahan baku, simplisia dan ekstrasi. Tidak jarang terjadi bahwa aset pengetahuan tradisional tentang obat diserap lalu diakui menjadi kekayaan intelektual perseorangan atau koorporasi berlevel multinasional, seperti pada kasus malaria. Sehingga demikian, sistem pewarisan pengetahuan pengobatan tradisional yang dilakukan secara lisan, turun temurun, terpilih dan tanpa dokumentasi tertulis yang disampaikan Noorcahyati dan Arifin (2014) bisa di argumentasikan sebagai suatu upaya masyarakat lokal dalam menghargai dan melindungi nilai kapital dari pengetahuan mereka dan sekaligus sebagai bentuk ketidakpercayaan akan profit sharing bila pengetahuan tersebut didokumentasikan.

Perspektif konservasi dalam penggalian, pemanfaatan dan pemanfaatan berkelanjutan tumbuhan obat sumberdaya hayati tidak terlepas dari karakter dan status konservasi tumbuhan tersebut. Kerumitan selalu muncul disaat jenis tumbuhan tertentu adalah jenis yang berasosiasi erat dengan habitat hutan, endemik dan atau dilindungi. Pada kasus ini, misalnya yang terjadi pada pasak bumi dan bidara laut, pengaruh kapital telah menempatkan para pemburu-pemburu dan pengumpul bahan baku untuk melakukan tindakan eksploitasi di hutan alam. Minimnya bekal pengetahuan tentang teknik panen dan konsep panen yang ramah lingkungan, contohnya pada kasus Dragon Blood (serbuk Rotan Jerenang), telah menyebabkan tingkat regenerasi tumbuhan rotan jerenang menurun drastis di habitatnya. Sehingga demikian, sistim pemanenan jenis-jenis tanaman HHBK (termasuk tumbuhan obat) yang bersifat tidak merusak yang disampaikan Rostiwati (2012) hanya terwujud apabila para pengumpul dibekali dengan pengetahuan tentang prinsipprinsip kelola yang lestari. 
Berikut pada Gambar 1 disampaikan konsep pikir tentang perspektif kehutanan dan lingkungan hidup berkenaan dengan upaya konservasi dan pemanfaatan tumbuhan obat dari sumber daya hutan.

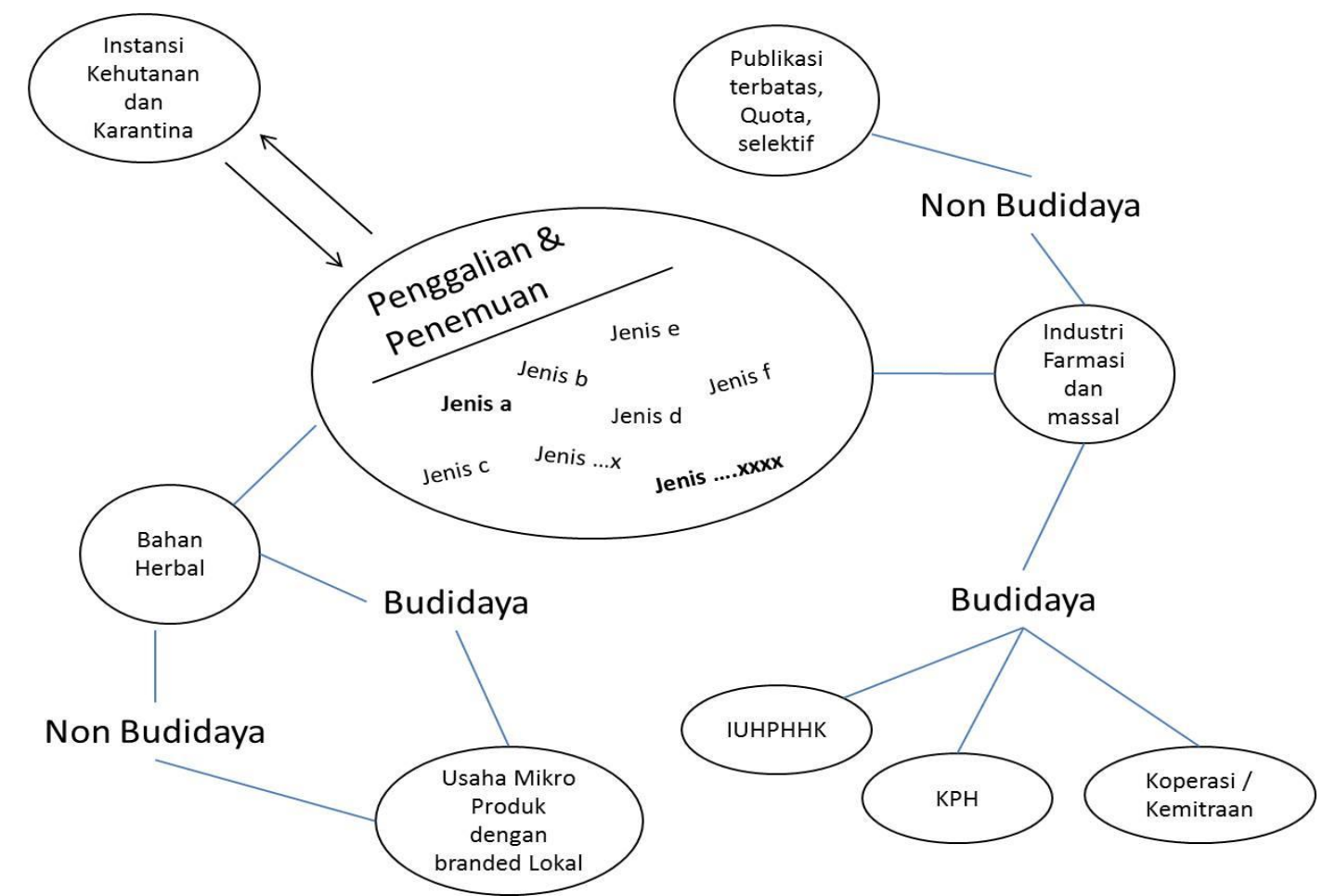

Gambar 1. Konsep pikir tentang perspektif kelola tumbuhan obat bersumber dari hutan

Dalam hal ini dijelaskan bahwa penggalian atau eksplorasi perlu dimulai dengan aktifitas verifikasi kawasan. Aktifitas ini penting untuk mengenali zonasi dalam kawasan, termasuk mengkoordinasikan tentang aksesibilitas. Terutama dalam kawasan konservasi, verifikasi ini secara resmi di atur dalam Surat Keputusan Direktur Jenderal Perlindungan Hutan dan Konservasi Alam Nomor : SK.192/IV-Set/HO/2006 tentang Izin Masuk Kawasan Suaka Alam, Kawasan Pelestarian Alam dan Taman Buru, atau yang lebih dikenal dengan istilah Simaksi (Surat Izin Masuk Kawasan Konservasi).

Verifikasi selanjutnya adalah melaporkan jenis target yang digali atau yang telah diperoleh setelah eksplorasi. Hal ini diperlukan untuk mengenali status konservasi jenis dimaksud, apakah termasuk jenis dilindungi atau tidak dilindungi. Proses ini juga memberi manfaat dalam mendapatkan informasi tentang habitus dan kelimpahan di dalam kawasan. Kumpulan informasi ini tentunya menjadi poin penting dalam penyusunan strategi untuk pemanfatan dan pemanfaatan berkelanjutan dari jenis dimaksud.

Terkait kebutuhan seleksi, karakteristik, aspek budidaya dan teknologi pemanenan serta pasca panen; dalam konsep pikir ini disampaikan perlunya menggolongkan jenis target/temuan ke dalam dua kelompok, yaitu sebagai herbal atau sebagai bahan baku industri jamu atau obat modern. Untuk jenis yang dikelompokkan sebagai herbal dan mempunyai karakater teknologi yang mudah dikuasai adalah jenis yang berpotensi untuk dikembangkan dalam usaha ekonomi daerah tempatan, baik dalam bentuk Usaha Kecil Obat Tradisional (UKOT) maupun Usaha Mikro Obat Tradisional (UMOT). Transfer teknologi dan pengetahuan tentang Cara Pembuatan Obat Tradisional yang Baik (CPOTB) serta pengetahuan teknologi panen dan budidaya menjadi kekuatan dalam pemanfaatan berkeberlanjutan jenis dimaksud. Strategi ini memiliki nilai penting untuk menjadikan 
produk-produk tumbuhan obat atau produk turunannya memiliki penciri atau branded daerah tempatan.

Terakhir, kehati-hatian sangat diperlukan untuk penemuan jenis yang dikelompokkan sebagai bahan baku obat untuk industri yang lebih besar dan berpotensi diproduksi secara massal dengan teknologi yang tinggi. Publisitas dalam hal ini perlu diperketat, atau paling tidak, telah mempertimbangkan status ancaman di masa depan. Terutama untuk jenis-jenis yang memiliki asosiasi yang kuat dengan habitat hutan. Pengaturan panen dan quota menjadi poin penting untuk mengantisipasi aktifitas eksploitasi yang berlebihan terhadap jenis target. Untuk jenis yang mempunyai potensi penggunaan jangka panjang, penelitian tentang teknologi penangkaran dan budidaya diperlukan. Dan bila telah dikuasai, sentra-sentra produksi dapat dikembangkan dengan membangun pertanaman. Potensi lahan untuk kegiatan ini diantaranya dapat dilakukan di dalam kawasan hutan produksi, yaitu dengan menjalin kerjasama dengan pemegang ijin usaha kehutanan kayu/bukan kayu (IUPHHK-IUPHHBK), Kesatuan Pengelolaan Hutan $(\mathrm{KPH})$ atau di zona pemanfaatan di kawasan konservasi. Kerjasama ini berpotensi dikembangkan dalam bentuk kemitraan bersama masyarakat sekitar hutan.

\section{F. PENUTUP}

Hadist dan ayat Qur'an berikut patut menjadi panduan kita dalam upaya penggalian, pemanfaatan dan pemanfaatan berkelanjutan tentang tumbuhan obat, sekaligus menjadi penutup dalam ulasan ini. "Sesungguhnya Allah menurunkan penyakit dan obat, dan menjadikan bagi setiap penyakit obatnya, maka (berobatlah kamu sekalian, tetapi) jangan berobat dengan yang haram." (HR. Abu Dawud)". "Dan janganlah kamu membuat kerusakan di muka bumi, sesudah (Allah) memperbaikinya dan berdo'alah kepada-Nya dengan rasa takut (tidak akan diterima) dan harapan (akan dikabulkan). Sesungguhnya rahmat Allah amat dekat kepada orang-orang yang berbuat baik" (Q.S. AlA'raf : 56).

\section{G. DAFTAR PUSTAKA}

Aditama, Y.T. 2014. Jamu dan Kesehatan. ISBN 978-602-0936-18-5. Lembaga Penerbit Balitbangkes (LPB). Jakarta.

BPS, 2015. Direktori Perusahaan Kehutanan. Biro Pusat Statistik (BPS). ISSN. 2089242x. Jakarta.

Cifor, 2007. Hutan dan Kesehatan Manusia. Editors : M, Wan; Y, Indriatmoko dan L, Yuliani CIFOR Infobrief No. 11(b), Mei 2007. Center for International Forestry Research (Cifor). Bogor.

Gardner, T dan R. Engelman. 1999. Forest Future : Population, Consumption, and Water Resourches. Population Action International. Washington DC.

Gunawan, W dan Mukhlisi. 2014. Bioprospeksi : Upaya Pemanfaatan Tumbuhan Obat Secara Berkelanjutan di Kawasan Konservasi. Prosiding Seminar Balitek KSDA : Tumbuhan Obat dari Hutan; Konservasi, Budidaya dan Pemanfaatan, Editors : I. Yassir, T, Atmoko dan B.S. Sitepu. Balai Penelitian Teknologi Konservasi Sumberdaya Alam, Balikpapan, 3 Desember 2014.

Kemenkes, 2007. Keputusan Menteri Kesehatan Republik Indonesia Nomor : 381/Menkes/SK/ III/2007 tentang Kebijakan Obat Tradisional Nasional.

Kementerian Kesehatan Republik Indonesia (Kemenkes). Jakarta.

Kemenkes, 2013. Peraturan Menteri Kesehatan Republik Indonesia Nomor 88 Tahun 2013 tentang Rencana Induk Pengembangan Obat Tradisional. Kementerian Kesehatan Republik Indonesia (Kemenkes). Jakarta. 
KLHK, 2015. Statistik Kementerian Lingkungan Hidup dan Kehutanan 2014. Pusat Data dan Informasi Kementerian Lingkungan Hidup dan Kehutanan (KLHK). Jakarta.

Kompas, $2015 . \quad$ Sebelum Hutan Menjadi Kenangan. http://nasional.kompas.com/read/2015/03/21/11422271/Sebelum.Hutan.Menjadi.Kenangan. Diakses : 12 April 2015.

PRI, 1990. Undang-undang Republik Indonesia Nomor 5 Tahun 1990 tentang Konservasi Sumberdaya Alam Hayati. Pemerintah Republik Indonesia (PRI), Jakarta.

$\mathrm{PRI}^{\mathrm{a}}$, 1999. Undang-undang Republik Indonesia Nomor 41 Tahun 1999 tentang Kehutanan. Pemerintah Republik Indonesia (PRI), Jakarta.

PRI $^{\text {b }}$, 1999. Peraturan Pemerintah Republik Indonesia Nomor 8 Tahun 1999 Tentang Pemanfaatan Jenis Tumbuhan Dan Satwa Liar. Pemerintah Republik Indonesia (PRI), Jakarta.

PRI, 2009. Undang-undang Republik Indonesia Nomor 36 Tahun 2009 tentang Kesehatan. Pemerintah Republik Indonesia (PRI), Jakarta.

Rostiwati, T. 2012. Rencana dan Progres Penelitian Pengelolaan HBBK Femo (Food, Energy, Medicine, Others) Lingkup Badan Litbang Kehutanan. Makalah Disampaikan Pada Seminar Nasional HHBK Tanggal 12 September 2012 Di Senggigi, Nusa Tenggara Barat.

Setyowati, F. M. (2010). Etnofarmakologi dan pemakaian tanaman obat suku dayak tunjung di Kalimantan Timur. Media Penelitian dan Pengembangan Kesehatan, 20(3 Sept).

Widuri, A.A.; Noorcahyati dan A. Puspanti. 2014. Kandungan Metabolit Sekunder pada Tumbuhan Berkhasiat Antidiabetes oleh Etnis Kalimantan : Potensi Untuk Pengembangan Obat Modern. Prosiding Seminar Balitek KSDA : Tumbuhan Obat dari Hutan; Konservasi, Budidaya dan Pemanfaatan, Editors : I. Yassir, T, Atmoko dan B.S. Sitepu. Balai Penelitian Teknologi Konservasi Sumberdaya Alam, Balikpapan, 3 Desember 2014. 